\title{
Building momentum toward underactive bladder research and education
}

\author{
Andrew Vereecke ${ }^{1} \cdot$ Michael Chancellor ${ }^{1}$
}

Received: 1 August 2015 / Accepted: 5 August 2015 / Published online: 14 August 2015

(C) Springer Science+Business Media Dordrecht 2015

\section{Editor,}

"Helpless"- that is how most patients feel when trying to manage underactive bladder (UAB). While treatments for overactive bladder $(\mathrm{OAB})$ have continued to improve and become more effective, there are still no effective treatments for patients with the converse condition-underactive bladder. This is a matter of increasing concern, especially as the burden of the condition is expected to rise with the aging global population. UAB is a name given to a group of troubling symptoms including hesitancy, straining, incomplete bladder emptying, and frequent urination or leakage due to overflow incontinence. The symptoms and severity of UAB vary between patients, and the course of the disease is often unpredictable. UAB is a multifactorial condition that can be caused by myogenic and neurogenic conditions as well as aging and medication side effects.

UAB is closely related to detrusor underactivity, which is an urodynamic-based diagnosis. Detrusor underactivity due to impaired detrusor contractility is the most classic pathology of the underactive bladder. Diseases such as diabetes and heart disease, or conditions that cause peripheral nerve damage are culprits of UAB also. And although many others are known, the scientific community has of yet been unable to create a working pathogenesis, let alone a standardized clinical definition.

A recent study in the International Urology Nephrology highlighted the levels of prevalence and lack of awareness of underactive bladder in the general population. The

Michael Chancellor

chancellormb@gmail.com

Andrew Vereecke

andrew.vereecke@beaumont.edu

1 Royal Oak, MI, USA survey revealed that $23 \%$ of men and women reported having a problem emptying the bladder completely yet only $11 \%$ had ever heard of UAB [1]. The problem of UAB is big and getting bigger with the aging population and rapidly increasing rate of diabetes that may result in diabetic bladder dysfunction.

It is only over the past 2 years that the term underactive bladder has become widely accepted and momentum is building for UAB to become a top priority in urology research over the next decade. We believe that the First International Congress for underactive bladder (CUREUAB), sponsored by the Aikens Center for Neurourology Research at Beaumont Health System, the Underactive Bladder Foundation, and the National Institute of Aging, was the catalyst that captured the global scientific community's interest in UAB. The First International CURE-UAB was held in February 2014 in Washington DC. The second international meeting is to be held in December 2015 in Denver, CO.

As a result of the first meeting in Washington DC, a special issue of International Urology and Nephrology [2] was published discussing disease definition, clinical guidelines, therapeutic directions, and suitable animal models to allow accurate testing of potential therapeutic candidates for UAB. Additional professional material and videos remain available online (www.underactivebladder.org). Another major outcome of the international meeting is the program announcement by the National Institutes of Health in December 2014 requesting new grant applications that focus on UAB (PA-15-049 Underactive Bladder in Aging) by the National Institute on Aging (http://www.nia.nih. gov).

While it is evident that we are bringing attention to $\mathrm{UAB}$, there is still a great need for research and education for UAB. We invite you to join us at the Second International 
Congress on Underactive Bladder (CURE-UAB) to learn more about underactive bladder and the current research efforts. You can access the meeting information at http:// meded.beaumont.edu/cure-uab. Together, we can change the paradigm to change the helplessness of UAB patients to hopefulness.

Funding This study was funded by the Aikens Neurourology Research Center at Beaumont Health.

\section{Compliance with ethical standards}

This editorial was written in compliance with ethical rules applicable to this journal and Beaumont Health.
Conflict of interest None.

Ethical approval This article does not contain any studies with human participants or animals performed by any of the authors.

\section{References}

1. Valente S, DuBeau C, Chancellor DD, Okonski J, Vereecke A, Doo F, Lajiness M, Diokno A, Chancellor MB (2014) Epidemiology and demographics of the underactive bladder: a cross-sectional survey. Int Urol Nephrol 46(Suppl 1):S7-S10

2. Chancellor MB, Diokno AC (2014) Frontier in urology; the underactive bladder. Int Urol Nephrol 46(Suppl 1):S1-S46 